\title{
LETRAMENTO LITERÁRIO E (A AUSÊNCIA DE) POLÍTICAS PÚBLICAS NACIONAIS E ESTADUAIS PARA O ENSINO DE LITERATURAS EM LÍNGUA INGLESA
}

\author{
Literary literacy and (the lack of) national and state public policies for teaching Literatures in \\ English Language
}

Daiane da Silva LOURENÇO - UEM

\begin{abstract}
RESUMO: Neste artigo, apresentamos discussões a respeito da teoria do Letramento, do Letramento Literário, dos Novos Letramentos e suas estreitas relações com os diferentes meios em que as Literaturas em Língua Inglesa (LLI) têm circulado no Brasil: histórias em quadrinhos, best-sellers, filmes, seriados, games, textos online. Apesar de os estudos de letramentos propiciarem a inserção das LLI no ensino básico brasileiro, por meio de ficções que têm sido constantemente lidas por estudantes, as políticas públicas educacionais discutidas (PCNs e DCEs do Paraná) não incentivam o trabalho com textos literários nas aulas de língua inglesa. Dessa forma, demonstramos a importância da inserção das LLI nas aulas da educação básica com o ensino baseado nos Novos Letramentos e no Letramento Literário como forma de suscitar reflexões sobre as diferenças sociais, culturais e identitárias.
\end{abstract}

PALAVRAS-CHAVE: letramento literário; literaturas em língua inglesa; ensino; PCNs; DCEs do Paraná.

\begin{abstract}
In this paper we present discussions concerning Literacy, Literary Literacy, New Literacies Studies and their close connections with different modes in which Literatures in English Language (LEL) have been circulating in Brazil: comic books, bestsellers, films, TV series, games, online texts. Although this theoretical approach facilitates the inclusion of LEL in Brazilian basic education, through fictions that have been consistently read by adolescents, the public policy education discussed (PCNs and DCEs of Paraná state) do not explicitly encourage teaching literary texts in English language classes. Thus, we demonstrate the importance of inserting LEL in basic education classes with teaching based on New Literacy Studies and Literary Literacy as a way of promoting reflections on social, cultural and identity differences.
\end{abstract}

KEYWORDS: literary literacy; Literatures in English Language; teaching; PCNs; DCEs of Paraná state.

\section{INTRODUÇÃO}

Estamos diariamente diante de novos perfis de leitores literários, os quais lidam não apenas com o escrito, mas com sons, vídeos, hiperlinks, a interatividade cada vez mais presente nos meios de comunicação. Para a compreensão destes novos leitores, também espectadores e internautas (CANCLINI, 2008), teorias como a Estética da Recepção, de Jauss, preocupada com a revisão da historicidade literária e a recepção de obras da Grande Literatura, ou ainda a Sociologia da Leitura, 


\section{DOSSIÊ ESPECIAL \\ JORDÃO (org.) Letramentos e Multiletramentos no Ensino de Línguas e Literaturas. \\ Revista X, vol.1, 2011}

que objetiva estudar a atuação do público e suas influências na produção e circulação das obras, não são suficientes. A relação dos novos leitores literários com a ficção está ainda mais complexa, visto a intensa circulação de textos multimodais e sua estreita relação com os mesmos. Relação muitas vezes íntima para os adolescentes contemporâneos e um tanto distante e, de certa forma, complicada para os pesquisadores que pretendem entendê-la.

Diante disso, acreditamos que uma nova abordagem teórica deve ser utilizada para a compreensão da leitura literária do início do século XXI, que se volte tanto para a ficção escrita quanto para a que circula em outros meios: o Letramento Literário. Apesar de seus estudos serem recentes, pesquisas vêm sendo desenvolvidas utilizando-o e procurando entender as novas formas de ficção em circulação no Brasil. Esta abordagem, contudo, ainda não atingiu as diretrizes públicas para o ensino de língua inglesa e respectivas literaturas em nosso país, dificultando, a nosso ver, ainda mais a presença das Literaturas em Língua Inglesa (doravante LLI) nas salas de aula das escolas públicas, pois esta tem circulado mais em meios não impressos entre os brasileiros.

Este artigo objetiva demonstrar a relevância da teoria do Letramento Literário como ponto de partida para o trabalho com ficções produzidas em língua inglesa nas escolas públicas. Devido à preocupação com o contexto do ensino de LLI na educação básica brasileira, mais especificamente no estado do Paraná, baseamo-nos nas orientações presentes nos Parâmetros Curriculares Nacionais (PCNs) e nas Diretrizes Curriculares Estaduais do Paraná (DCEs) para mostrar como faltam políticas públicas nacionais e estaduais voltadas para o ensino de LLI, para tanto estabelecemos um paralelo com a abordagem da literatura brasileira em tais documentos.

\section{A PROPOSTA DO LETRAMENTO LITERÁRIO}

Os estudos sobre o letramento no Brasil são recentes, porém, ao mesmo tempo têm alcançado destaque devido ao grande número de pesquisadores dedicando-se a estudá-lo e a aplicá-lo. Há ainda entre alguns acadêmicos e professores a dúvida em relação ao conceito de letramento, pois por muito tempo foi entendido e comparado com alfabetização. Kleiman (1995) afirma que o conceito de letramento começou a ser usado nos meios acadêmicos como tentativa de separar os estudos sobre o "impacto social da escrita" dos estudos sobre a alfabetização.

O conceito de alfabetização refere-se a competências individuais no uso e na prática da escrita (KLEIMAN, 1995) - não incluímos aqui a forma como Paulo Freire abordou a alfabetização. Um sujeito alfabetizado, neste sentido, consegue utilizar a leitura e a escrita para realizar atividades de seu cotidiano. A escrita como um ato de codificação da língua e a leitura como mera 
decodificação. Para Rojo (2009, p. 98), a alfabetização tem um foco individual, bastante ditado pelas capacidades e competências (cognitivas e linguísticas) escolares e valorizadas de leitura e escrita (letramentos escolares e acadêmicos). Alfabetizar é um processo que sempre esteve presente na e visto como função da escola. Mesmo com os estudos sobre o letramento, estudiosos (JUNG, 2003; KLEIMAN, 1995; ROJO, 2009; SIGNORI, 1995) ainda acreditam que a escola se atém a alfabetização.

Seguindo por uma vertente mais social, os estudos sobre o letramento dedicam-se aos usos da escrita e da leitura em diversos grupos sociais. Segundo Kleiman (1995), o termo letramento (literacy em inglês) foi cunhado no Brasil por Mary Kato, em 1986. Já Rojo (2009) enfatiza a importância da obra de Street (1984), que deu início aos Novos Estudos do Letramento (New Literacy Studies), ainda presentes em todo Brasil ${ }^{1}$. Como os estudos ainda podem ser considerados recentes, a palavra letramento não tem uma conceituação única e não está dicionarizada.

Street $(1984 ; 1993)$ relaciona letramento a práticas sociais. A partir de seus estudos, Kleiman (1995) define letramento como um conjunto de práticas sociais que usam a escrita, como sistema simbólico e como tecnologia, em contextos específicos, para objetivos específicos. Neste caso, destacam-se os impactos sociais da escrita e da leitura, que estarão relacionados com mudanças políticas, sociais e econômicas. Ser letrado é saber utilizar socialmente a tecnologia da escrita, em diferentes práticas de letramento, sejam elas valorizadas ou não, locais ou globais, recobrindo contextos sociais diversos (família, igreja, trabalho, mídias, escola etc.) (ROJO, 2009).

O letramento sob tal perspectiva permite aceitar que existem pessoas não alfabetizadas que são letradas, e alfabetizados não letrados para determinadas práticas sociais. Um senhor analfabeto que trabalha em uma feira vendendo verduras é letrado o suficiente para conseguir lidar com a compra e venda de seus produtos. Uma criança que ainda não foi alfabetizada consegue, atualmente, com muita facilidade, acessar a internet em busca de seus jogos favoritos. No entanto, um adulto alfabetizado pode não conseguir acessar a internet, ainda que consiga ler, com a mesma facilidade que a criança. Um adulto alfabetizado pode não conseguir jogar vídeo game. Isso implica dizer que somos letrados em diferentes momentos de nossa vida. Jung (2003), baseada em Barton e Hamilton (2000), afirma que

\footnotetext{
As pessoas adquirem diferentes letramentos associados com os diferentes domínios da vida. Elas desempenham papéis sociais que exigem usos particulares da escrita. (...) Além disso, os papéis sociais das pessoas podem mudar, o que significa que a pessoa pode participar com maior frequência de eventos de letramento em algumas fases da vida do que em outras (JUNG, 2003, p. 64).
}

\footnotetext{
${ }^{1} \mathrm{O}$ grupo de pesquisa Novos letramentos, multiletramentos e o ensino de línguas estrangeiras (USP), do qual fazemos parte, dedica-se a tais estudos.
} 


\section{DOSSIÊ ESPECIAL \\ JORDÃO (org.) Letramentos e Multiletramentos no Ensino de Línguas e Literaturas.}

Revista X, vol.1, 2011

Como participamos de diferentes domínios sociais, possuímos diferentes letramentos, no plural. Devido a tal variedade de letramentos, pessoas não alfabetizadas podem ser consideradas letradas em algumas situações.

O conceito de letramento de Kleiman (1995), que citamos anteriormente, menciona o uso da escrita como tecnologia. A tecnologia, termo muito utilizado atualmente, se refere ao uso de instrumentos para que o homem aja sobre a natureza. Sendo assim, a tecnologia da escrita (termo que se refere à escrita e à leitura) é o instrumento utilizado por nós para agirmos em diferentes contextos sociais.

Quando nos referimos aos estudos do letramento, devemos lembrar que o conceito de letramento apresentado foi desenvolvido pelos estudos linguísticos, com a intenção já apresentada de diferenciá-lo da alfabetização. Em nosso caso, nos apropriamos do conceito de letramento para os estudos literários. Para tanto, baseamo-nos nos estudos de Zappone (2008):

\footnotetext{
A apropriação do conceito de letramento ao campo dos estudos literários pode ser pertinente, se operarmos uma modulação fundamental: trabalhar com a escrita mencionada no conceito, mas compreendida dentro de algumas especificidades concernentes aos textos literários. Assim, podemos acatar o conceito de letramento nos estudos literários, propondo a noção de letramento literário enquanto o conjunto de práticas sociais que usam a escrita literária (ZAPPONE, 2008, p. 29).
}

No entanto, antes de prosseguirmos, consideramos importante pensar a respeito do conceito de literatura. O que é literatura? Quando e por que consideramos uma obra como literária?

As respostas para tal pergunta são múltiplas e sujeitas a modificações de acordo com o momento, o contexto e a perspectiva adotada (EAGLETON, 1983; CULLER, 1999; CANDIDO, 2002; HANSEN, 2005). Os documentos que regem o ensino de literatura no Brasil não apresentam uma definição explícita. Os Parâmetros Curriculares Nacionais do Ensino Médio (2000) afirmam que o conceito de texto literário é discutível. Tanto que mencionam como exemplo a fala de alunos questionando porque Machado de Assis é literatura e Paulo Coelho não. Enquanto para as Diretrizes Curriculares de Língua Portuguesa do Estado do Paraná (2009), o entendimento do que seja o produto literário está sujeito a modificações históricas, devendo ser considerado o contexto de produção, a crítica literária, a linguagem, a cultura, a história, a economia, entre outros.

Assim, tomamos como base fundamental para nossas discussões sobre literatura Hansen (2005) que vê a literatura como ficção. A ficcionalidade das obras literárias é destacada pelo teórico como um caráter apontado há séculos, é a figuração fingida do possível comparada com fatos reais e verdadeiros. "A ficção é um ato de fingir o possível, ou seja, é um ato pseudo-referencial [faz referência a algo que não é verdade] e, ainda, auto-referencial [fala de si mesma]" (HANSEN, 2005, 
p. 17). Zappone (2008) se apropria do conceito de Hansen para seus estudos e o amplia, considera o literário como uma escrita imotivada, gratuita, cuja marca principal é a ficcionalidade que se opera em diferentes formas de figuração mimética (dramática, lírica, narrativa, épica). Para a estudiosa, o caráter de ficcionalidade aponta que a escrita literária pode ser compreendida não apenas como aquela materializada por meio do impresso, do grafado, mas como uma forma discursiva que possui certos traços textuais e que pode ou não ser veiculada por meio do escrito.

Tentar definir o que é literatura é uma tarefa árdua, pois os limites entre o literário e o nãoliterário são tênues, entretanto a ficcionalidade é apontada aqui como uma de suas características por ser uma forma de justificar a inserção de textos não impressos nos estudos de letramentos. Jogos, filmes, histórias em quadrinhos, hipertextos costumam não ser considerados literários, apesar de possuírem algumas características da literatura, a principal sendo a ficcionalidade. Apesar disso, acreditamos que outros elementos são importantes para considerar um texto literário: a escrita imaginativa (EAGLETON, 1983), a "estranheza" do texto (EAGLETON, 1983), a expressão da sociedade (CANDIDO, 1985), a gratuidade (CANDIDO, 1985), a linguagem específica (CULLER, 1999), a intemporalidade e a universalidade (COMPAGNON, 2001), o contraste com gêneros pragmáticos (HANSEN, 2005), entre outros. A presença de tais elementos faz com que um texto seja considerado literário, entretanto os estudos de Novos Letramentos voltam-se também para narrativas não-impressas, as quais nem sempre possuem todas estas características, mas algumas especificidades literárias. Zappone (2008) volta-se principalmente para a ficcionalidade, gratuidade e imotivação para justificar o caráter literário de outras formas de narrativas que começam a ganhar destaque, mas outros elementos também aparecem, como a expressão de um contexto social específico.

A escola é considerada a agência de letramento mais importante para a sociedade. Contudo, em geral, está ainda preocupada com o processo de alfabetização dos alunos, a codificação e decodificação, visto por esta instituição como competência individual fundamental para a vida adulta, influenciadora nos estudos e na situação econômica. O letramento ainda não tem muito espaço no ambiente escolar, pois a inserção de um ensino baseado em práticas e contextos sociais tem começado a ganhar ênfase nas diretrizes e cursos voltados para os profissionais da educação básica. Outras agências de letramento, como a família, a igreja, o trabalho, ensinam letramentos diferentes da escola. Segundo Kleiman (1995), as práticas de uso da escrita na escola sustentam-se num modelo de letramento considerado equivocado por muitos pesquisadores: modelo autônomo. Street (1993, p. 5) utiliza o termo "autônomo" como forma de conceituar "um modelo de letramento visto em termos técnicos, tratando-o como independente do contexto social, uma variável autônoma 
cujas consequências para a sociedade e a cognição podem ser derivadas de sua natureza intrínseca" (tradução nossa). Essa concepção de letramento pressupõe que há apenas uma maneira de o letramento ser desenvolvido, sendo que essa forma está associada quase que causalmente com o progresso, a civilização, a mobilidade social. É um modelo que apenas desenvolve habilidades cognitivas. A "autonomia" refere-se à escrita vista como um produto em si mesmo, lógica, fechada, sem ter relação com o contexto de sua produção para ser interpretada. Kleiman (1995) explica que as principais características deste modelo são estabelecer uma relação entre a aquisição da escrita e o desenvolvimento cognitivo, ou seja, quem sabe escrever é "pensa melhor"; e separar oralidade e escrita, inferiorizando a primeira.

Tais características são muitas vezes tidas como verdadeiras pela sociedade que enfatiza a importância de saber ler e escrever, dissociados de um contexto. Quem sabe ler e escrever é considerado mais "inteligente”, tem mais conhecimento, pensa melhor. Logo, terá mais status social, conseguirá melhores empregos. Além disso, a escrita recebe mais importância que a oralidade, o que faz com que povos que não desenvolveram a escrita sejam considerados "primitivos", inferiores aos "civilizados". Esta forma de ver a escrita é chamada mito do letramento, a crença de que o conhecimento das letras está ligado ao sucesso social e a um maior desenvolvimento cognitivo. Por estes motivos, a escola ao se pautar no modelo autônomo responsabiliza os estudantes de classe baixa por seu próprio fracasso, por terem um desempenho individual ruim. Esta perspectiva acredita que o letramento traz resultados homogêneos na sala de aula e o fracasso escolar de alguns alunos é de sua própria responsabilidade.

Em contraposição ao modelo autônomo, há o modelo ideológico, que considera os contextos de práticas de letramento. Segundo Street (1993, p. 7), este enfoque de letramento "passa a ver as práticas de letramento como indissoluvelmente ligadas às estruturas culturais e de pode da sociedade, e a reconhecer a variedade de práticas culturais relacionadas à leitura e escrita em diferentes contextos" (tradução nossa). Este modelo baseia-se em práticas sociais, no uso da escrita por diferentes grupos e contextos. Para o modelo ideológico, além das instituições educacionais há outras agências de letramento, tão importantes quanto a escola, pois cada uma utiliza um letramento específico. A leitura e a escrita são vistas como práticas sociais que servem a um propósito, não são um fim em si mesmas. São exemplos de práticas sociais: ir ao mercado, assistir filme legendado, jogar vídeo game.

Rojo (2009, p. 99) conceitua letramento como práticas tão diferentes, em contextos tão diferenciados, embora diferentemente valorizadas e designando a seus participantes poderes também diversos. Poderíamos então, pensando na escrita literária, dizer que letramento literário são práticas 
de leitura literária tão diferentes, em contextos tão diferenciados, embora diferentemente valorizadas e designando a seus participantes poderes também diversos. Zappone (2008) se apropria do conceito de letramento de Kleiman (1995) para a literatura o apontando como o conjunto de práticas sociais que usam a escrita ficcional ou escrita literária enquanto sistema simbólico e enquanto tecnologia em contextos específicos e para objetivos específicos. Neste sentido, são considerados literatura não apenas os "clássicos", mas também textos julgados como menores²: bestsellers, histórias em quadrinhos, versões fílmicas de literatura, games baseados em textos literários, já que todos são escritas ficcionais. Em outras palavras, da perspectiva do Letramento Literário as obras citadas não são consideradas "superiores" ou "inferiores", mas todas são narrativas com elementos literários que podem ser estudadas e trabalhadas nas aulas de língua inglesa.

Acreditamos que diante dos estudos de Street (1993) e Kleiman (1995) e com o intuito de estudarmos aspectos literários norteando-nos pelos letramentos, podemos considerar o ensino de literatura presente nas escolas (apesar do predomínio de literatura brasileira em detrimento das LLI) também dentro de um modelo autônomo e um ideológico. Seguindo o modelo autônomo, a literatura seria apresentada aos alunos por meio da periodização literária ou utilizada como um meio para estudo de aspectos linguísticos ou apenas mais um gênero a ser estudado nas aulas, sendo que seriam considerados literários apenas os "cânones" da literatura, na forma impressa e grafada. Neste modelo, os sentidos dos textos literários são apresentados prontos e inquestionáveis por críticos e estudiosos. Sendo assim, os alunos não são ensinados a ler criticamente, visto que o texto literário é visto apenas como uma estrutura, lido como os outros gêneros são lidos na maior parte das vezes, em busca de informações e aspectos linguísticos específicos. Já o modelo ideológico veria a literatura como textos ficcionais sujeitos a modificações históricas, sua relação dialógica com outros textos, o contexto de produção, a linguagem, o leitor, e sua circulação em outras formas além da grafada. Como afirma Zappone (2008), a escrita literária como uma forma discursiva que possui certos traços textuais e que pode ou não ser veiculada por meio do escrito. Escrito, neste caso, refere-se à grafia, enquanto o termo escrita está relacionado a enunciado, texto. Sendo assim, diferentes formas de ficção seriam consideradas: adaptações, traduções, HQs, mangás, mashups, fanfics, filmes. Este modelo interessa-nos ao sugerirmos a inserção de outras formas de ficção nas aulas de LLI.

Tais obras não são consideradas literárias por muitos estudiosos (CHIARETTO; 2003; HANSEN, 2005) pelo fato de fazerem parte da indústria cultural, no entanto têm especificidades

\footnotetext{
${ }^{2}$ A partir dos estudos dos letramentos, não são feitas distinções entre os gêneros narrativos. Esclarecemos que apesar de não concordarmos com o emprego de termos como "clássicos" e "cânones" para tratar de obras literárias consagradas e "best-sellers" ou "literatura de massa" para abordar romances que não são considerados literários por muitos críticos da literatura e professores, os utilizamos na falta de outra terminologia. Para nós, estas obras não devem ser colocadas como superiores e inferiores, pois são produzidas para fins e públicos diferentes, tendo suas especificidades.
} 


\section{DOSSIÊ ESPECIAL \\ JORDÃO (org.) Letramentos e Multiletramentos no Ensino de Línguas e Literaturas. \\ Revista X, vol.1, 2011}

literárias, como a ficção, o caráter de gratuidade, a linguagem especifica. Pesquisas realizadas (MAFRA, 2003; ROCCO, 1992; VERSIANI, 2003) mostram que os adolescentes têm lido cada vez mais estas obras, muitas produzidas em língua inglesa e traduzidas, e questionam porque não são consideradas literatura e não circulam no ambiente escolar. A crença de que as pessoas que leem literatura erudita são pessoas melhores é uma das explicações para a recusa escolar em inserir as outras formas de ficção no currículo. Entretanto, Menezes de Souza (2007) afirma que o letramento não é mais visto como uma tecnologia ou habilidades cognitivas a serem desenvolvidas em cada indivíduo, mas como uma prática sócio-culturalmente situada que envolve construções de significados. Sendo assim, o estudioso considera que todos os letramentos em certo sentido devem ser críticos. Então, todas as formas de narrativas, que circulam na forma escrita ou não, em diferentes meios, podem ser lidas criticamente

Para compreendermos a relação de leitores literários com estas novas formas de ficção, principalmente as produzidas em língua inglesa, é importante conhecermos os conceitos de evento e práticas de letramento na escola e em outras instituições.

Jung (2003) considera evento de letramento uma situação específica em que a escrita constitui parte essencial para fazer sentido. A interação entre os participantes, por meio de um texto, e os processos e estratégias interpretativas constituem o evento. O evento se refere ao uso da escrita. São exemplos de evento de letramento: a leitura de um livro, a discussão do conteúdo de um jornal com amigos, a organização de uma lista de compras, jogar vídeo game, assistir filme legendado, enviar uma mensagem por celular. Dentre tais atividades, as que envolvem novas tecnologias são mais desenvolvidas entre os jovens, hoje. Estão diariamente envolvidos em eventos de letramento ligados à ficção em meios não impressos.

A prática de letramento está relacionada aos comportamentos dos participantes em um evento de letramento, que determinam o sentido dos usos da escrita. Seria o modo como os sujeitos produzem sentido para o texto, o como, em uma situação particular. Por esta razão, em um mesmo evento pode haver práticas de letramento diferentes.

Jung (2003) acrescenta que os modos de fazer uso da escrita e da leitura são historicamente construídos, assim os eventos de letramento e as práticas de letramento também são historicamente construídos. Neste sentido, os estudos voltados para Novos Letramentos são relevantes. O fato de crianças e adolescentes não se interessarem tanto pela leitura de obras literárias grafadas, por exemplo, é explicado pelo contexto no qual estão inseridas. Hoje os adolescentes são multiformes, veem TV, usam a internet e falam ao telefone ao mesmo tempo. Os suportes da escrita ficcional estão cada vez mais diversificados devido aos meios digitais. 
As práticas de letramento literário centradas em textos eruditos que ocorrem em sala de aula muitas vezes são rejeitadas pelos estudantes. No entanto, eles interessam-se por narrativas muitas vezes marginalizadas pelas instituições de ensino, e realizam práticas letramento literário em casa, em sites e blogs da internet, em clubes de leitura, em discussões com amigos, lendo histórias em quadrinhos, vendo filmes, jogando vídeo games, lendo fanfics. Muitas destas produções geralmente são produzidas em língua inglesa e os alunos que têm fluência na língua têm contato com o texto em inglês enquanto outros leem a tradução. De toda forma, os alunos lidam cotidianamente com expressões culturais diferentes das suas próprias e que podem contribuir muito para a sua formação enquanto cidadão, ao contrapor a cultura que está tendo contato com a brasileira e ao lidar com outras identidades nacionais, repensando seu próprio conceito de nacionalidade e identidade. Para tanto, consideramos que o trabalho do professor de inglês com estas novas formas de letramento em sala de aula é relevante para um direcionamento crítico.

Além da perspectiva de letramento de Street (1984; 1993) e Kleiman (1995) e do letramento literário proposto por Zappone (2008), que adotamos neste trabalho, há estudos relevantes sobre Novos Letramentos e o ensino de literaturas em língua inglesa desenvolvidos no Brasil por Menezes de Souza (2007), Wielewicki (2002; 2007), Monte Mór (2007), Festino (2007; 2008). Nestes estudos, o letramento é visto como o uso da leitura e da escrita como prática social. Monte Mór (2007) afirma que esta visão permitiu o desenvolvimento de estudos de vários letramentos (visual, digital, multicultural, multimodal) como forma de propiciar um processo educacional no qual o ensino da leitura é inseparável do ensino de culturas. Ainda, os leitores são levados a entender representações textuais, valores, ideologias, discursos, demonstrando posicionamentos sobre questões sociais e uma visão de mundo, além da percepção de que a leitura está relacionada à distribuição de conhecimento e poder na sociedade.

Como vemos, para as literaturas em língua inglesa, os Novos Letramentos são uma forma de inserir narrativas nas aulas de inglês da educação básica e propiciar discussões. Ao invés de os textos de LLI serem uma forma de imposição de "verdades" e valores dos Estados Unidos ou da Inglaterra, devido à sua influência econômica sobre os outros países, o que faz com que estudantes rejeitem esta disciplina ao considerá-la uma forma de "idolatria" à obras inglesas e estadunidenses, Festino (2008) sugere uma mudança de enfoque ao estudar o texto literário: "de uma visão dominante, que se preocupa em ensinar autores e valores tidos como universais, a uma visão do texto literário como 'encontro de culturas', (...) que leva em conta a diferença" (2008, p. 177).

As justificativas para o ensino de literaturas em língua inglesa na educação básica a partir de Novos Letramentos são: a sala de aula de literatura ser um espaço oportuno para a discussão de 


\section{DOSSIÊ ESPECIAL \\ JORDÃO (org.) Letramentos e Multiletramentos no Ensino de Línguas e Literaturas. \\ Revista X, vol.1, 2011}

leituras em conjunto, expandindo as possibilidades interpretativas dos alunos, que não seriam as mesmas se a leitura fosse feita apenas individualmente; o contato com o outro, estrangeiro, ao ler textos produzidos em países falantes da língua inglesa, possibilitando conhecer a identidade do outro e a própria, assim como ter noções de nacionalismo; a contribuição para a formação ao ter de lidar com outras posturas de forma crítica e com a sua própria (WIELEWICKI, 2002). Festino (2008) acrescenta que quando uma literatura nacional torna-se literatura estrangeira (como as em língua inglesa no Brasil) devemos lembrar que esses textos irão modificar a maneira de significar de seu contexto de origem e adquirir novas significações no contexto de chegada, dependendo das relações entre as duas culturas. Isto explica, para nós, o fato de algumas pessoas rejeitarem produções dos Estados Unidos, principalmente, ao considerarem este país um dominador em relação ao Brasil. Nas palavras de Festino (2008, p. 190), “os valores de uma cultura podem se tornar preconceitos ao serem recriados em um contexto de enunciação diferente". Por isso, a relevância de uma abordagem das LLI na educação básica considerando a construção de significados por parte do leitor e sua capacidade de recriar o que lê a partir de seu contexto.

Apesar de tantas justificativas e as teorias de letramentos para o ensino de LLI, no contexto brasileiro faltam políticas públicas nacionais e estaduais para a inserção de LLI na educação básica, assim como a aplicação do letramento literário em sala de aula. Por isso, abordamos a seguir documentos que ditam diretrizes para o ensino de língua inglesa no ensino fundamental e médio e a forma como as LLI são (ou não) abordadas.

\section{A AUSÊNCIA DA TEORIA DE LETRAMENTO LITERÁRIO E DO ENSINO DE LLI EM POLÍTICAS PÚBLICAS EDUCACIONAIS DO BRASIL E DO PARANÁ}

A escola, apesar de ser a principal agência de letramento, se torna por vezes a última opção dos adolescentes quando procuram sugestões de leitura literária, isto porque o discurso escolar visa a aquisição de bens culturais de prestígio pelos alunos. Ao pensar em literatura, seria a leitura de obras “clássicas", as quais eles costumam rejeitar. A escola deveria considerar o fato de que as práticas de letramento literário são historicamente construídas, no entanto, já vimos que ainda há o predomínio do modelo autônomo no ambiente escolar, do ensino de literatura periodizado, do estudo dos cânones de acordo com leituras de críticos e especialistas.

Afirmamos anteriormente que existem algumas especificidades literárias apontadas por estudiosos e, por isso, algumas formas de narrativa não são consideradas literatura. No entanto, o Letramento Literário proporciona o estudo de textos a partir de diferentes grupos e contextos sociais, 
sem estabelecer diferenças hierárquicas entre eles. Apesar disso, alguns manuais e livros didáticos ainda empregam, muitas vezes, uma distinção antiga entre os textos fictícios e os textos considerados pragmáticos, isto é, os textos "falsos" e os "verdadeiros"; e consideram requisitos necessários para que uma leitura efetivamente literária aconteça, os quais para Hansen (2005) seriam o envolvimento com o texto por meio de um ato de fingir; o reconhecimento do texto literário como figuração mimética; o conhecimento da historicidade da forma e das convenções da escrita literária; ter em consideração a materialidade dos suportes dos textos. Para o autor, se o leitor não possuir uma mínima noção de tais requisitos, fará uma leitura do texto, porém não será uma leitura literária.

Segundo Hansen (2005), os programas de leitura escolar estão cientes da especificidade literária, tanto que a discernem de outras leituras e descrevem como deve ser desenvolvida:

\footnotetext{
É um pressuposto deles que, por ser gratuita, não-pragmática ou interessadamente desinteressada, a leitura de ficção deverá levar o leitor escolar a objetivar sua experiência individual, pondo-se a si mesmo entre parênteses como sujeito social de hábitos perceptivos quando faz a experiência da liberdade imaginária dos possíveis da ficção. Nos programas, essa experiência de auto-distanciamento e relativização do vivido imediato é, como disse, descrita genericamente como "atitude crítica", "reflexão", "auto-conhecimento", "conhecimento da realidade do país" etc. Conforme essas orientações, a leitura literária teria a função de desautomatização de hábitos, formação crítica do imaginário, esclarecimento democrático, aculturação e socialização do estudante. Contrastando tecnicamente com a leitura pragmática e a leitura científica, seria antes de tudo crítica, opondo-se politicamente à ideologia (HANSEN, 2005, p. 42).
}

Esta citação demonstra que Hansen acredita que os programas escolares brasileiros reconhecem a importância da literatura para a formação crítica dos estudantes. Como Hansen é professor e pesquisador de Literatura Brasileira, sua crítica refere-se a textos em língua portuguesa, cujo valor cultural já foi considerado por críticos e professores. Contudo, com as literaturas em língua inglesa a situação é oposta no contexto brasileiro. Apesar de as aulas de língua inglesa fazerem parte obrigatoriamente do currículo escolar, suas respectivas literaturas não aparecem nas diretrizes do governo. Para mostrarmos o contraste entre a literatura brasileira e as literaturas em língua inglesa nas políticas públicas, começamos por expor como a primeira aparece em documentos que norteiam o ensino da educação básica.

Para orientar a leitura na sala de aula tanto do Ensino Fundamental e Médio quanto dos próprios cursos de Letras, que procuram seguir o ensino dentro das propostas direcionadas aos professores, há documentos do governo criados para que a educação do país siga na mesma direção: os Parâmetros Curriculares Nacionais (PCNs). No estado do Paraná, o governo optou por criar suas próprias orientações, inseridas nas Diretrizes Curriculares Estaduais (DCEs). Em ambos, entretanto, as propostas focam principalmente a literatura erudita, praticamente sem espaço para outras narrativas, ou seja, para outras formas de letramento literário. Quando outras formas de ficção são 


\section{DOSSIÊ ESPECIAL \\ JORDÃO (org.) Letramentos e Multiletramentos no Ensino de Línguas e Literaturas. \\ Revista X, vol.1, 2011}

sugeridas para o ensino, são inseridas como gêneros do discurso e trabalhadas por meio de análises que não priorizam o literário, e sim aspectos linguísticos.

Os PCNs de Língua Portuguesa do terceiro e quarto ciclo do Ensino Fundamental (1998) abordam o letramento para o ensino em sala de aula. Consideram a leitura uma forma de atuação social, por isso afirmam que todo cidadão possui um tipo de letramento que o permite participar das situações sociais, envolvendo ou não a escrita e a leitura. As práticas de leitura se diferenciam historicamente e dependem do contexto de cada leitor. A proposta dos PCNs é de que o professor deve considerar o aluno e seu contexto. As orientações rejeitam um ensino voltado para a extração de informações e a análise de unidades básicas (sílabas, palavras, frases) descontextualizadas, o ensino deve ser fundamentado no texto. Tais orientações condizem com a proposta do Letramento Literário.

Os PCNs de Língua Portuguesa têm parâmetros voltados especificamente para a literatura e a preocupação em esclarecer o que é entendido como literário. Uma parte dedicada à literatura brasileira explicita que "o texto literário constitui uma forma peculiar de representação e estilo em que predominam a força criativa da imaginação e a intenção estética" (BRASIL, 1998, p. 26). Entre outras especificidades, a literatura é descrita como um "inusitado tipo de diálogo", repleto de "invenções de linguagem" e "subjetividade", uma "forma de produção de conhecimento" diferenciada. Para realizar sua leitura é necessário reconhecer suas singularidades e propriedades e afastar equívocos que costumam acontecer na escola, isto é, "tomá-lo como pretexto para o tratamento de questões outras (valores morais, tópicos gramaticais) que não aquelas que contribuem para a formação de leitores capazes de reconhecer as sutilezas, as particularidades, (...) a profundidade das construções literárias" (BRASIL, 1998, p. 27).

Apesar de a proposta ser baseada em letramentos, sabemos que o ensino tradicional de literatura, centrado em períodos, ainda predomina nas escolas, pois a teoria ainda é pouco aplicada no ensino. Mesmo assim, há a preocupação dos redatores em discorrer sobre a literatura brasileira e sua relevância para a formação dos estudantes. Em contrapartida, nos Parâmetros Curriculares Nacionais de Língua Estrangeira para o terceiro e quarto ciclos do Ensino Fundamental (1998), não encontramos qualquer menção à literatura. As orientações para o ensino de outra língua no país são estritamente linguísticas, voltadas principalmente para a leitura a fim de ampliar o conhecimento do aluno e atender às exigências de exames como o vestibular e admissão a cursos de pós-graduação. A justificativa é a de que somente nestes casos a maioria dos cidadãos brasileiros tem contato com a língua inglesa, poucos têm a oportunidade de usá-la oralmente ou na forma de produção escrita. Para os PCNs de LE, o ensino de outra língua: 
leva a uma nova percepção da natureza da linguagem, aumenta a compreensão de como a linguagem funciona e desenvolve maior consciência do funcionamento da própria língua materna. Ao mesmo tempo, ao promover uma apreciação dos costumes e valores de outras culturas, contribui para desenvolver a percepção da própria cultura por meio da compreensão da(s) cultura(s) estrangeira(s). O desenvolvimento da habilidade de entender/dizer o que outras pessoas, em outros países, diriam em determinadas situações leva, portanto, à compreensão tanto das culturas estrangeiras quanto da cultura materna. Essa compreensão intercultural promove, ainda, a aceitação das diferenças nas maneiras de expressão e de comportamento (BRASIL, 1998, p. 37).

Estes aspectos que o documento ressalta para a formação do estudante podem ser alcançados com a leitura de LLI, pois o contato com a cultura do outro e as diferenças será ainda maior. Contudo o documento não faz menção ao uso de literaturas nas aulas de línguas estrangeiras, apesar de a maioria dos alunos já estar diariamente exposta à textos produzidos em outras línguas, por meio de ficções em HQs, best-sellers, filmes, seriados. A inserção de tais ficções em sala de aula orientadas pelo Letramento Literários permite um direcionamento mais crítico das leituras dos alunos.

Nos PCNs do Ensino Médio (2000), o texto literário já não é tratado como uma leitura com especificidades próprias, mas citado como um gênero discursivo em meio a tantos outros. A literatura brasileira é sugerida no currículo como mais um gênero a ser abordado nas aulas. Em relação as Línguas Estrangeiras, novamente a literatura não aparece, apenas a preocupação com a competência linguística do aluno, relacionada à formação para o trabalho. Sendo assim, os Parâmetros Curriculares Nacionais não propõem a inserção das literaturas nas aulas de língua estrangeira da educação básica brasileira.

As Diretrizes Curriculares Estaduais do Estado do Paraná (DCEs) foram criadas a fim de dar uma atenção maior à realidade do estado, visto que os PCNs englobam o país todo. As DCEs de Língua Portuguesa (2008) postulam a linguagem como um fenômeno social e dialógico, baseando-se na teoria de Bakhtin, enfatizam a interação e o ensino de diferentes gêneros discursivos. $\mathrm{O}$ letramento do aluno, visto como práticas de uso social da leitura e da escrita, também deve ter prioridade em sala de aula. A leitura é vista como um "ato dialógico", "interlocutivo", que envolve questões sociais, políticas, econômicas, históricas, ideológicas e ativa os conhecimentos prévios do leitor. A leitura acontece por meio da recepção, da resposta do leitor, o qual produz significados.

Uma parte deste documento aborda o ensino de literatura brasileira em sala de aula. O texto literário é considerado parte da vida social e a concepção de literatura está sempre sujeita a modificações históricas. No entanto, o documento está centrado no ensino de literatura "clássica", pois não faz menção a outras formas de ficção ou letramentos, no plural. Baseando-se em Candido (1972), as DCEs consideram a produção literária humanizadora. Além disso, enfatizam a importância do papel do leitor e fundamentam-se nas seguintes teorias: 


\begin{abstract}
Sob esse enfoque sugere-se, nestas Diretrizes, que o ensino da literatura seja pensado a partir dos pressupostos teóricos da Estética da Recepção e da Teoria do Efeito, visto que essas teorias buscam formar um leitor capaz de sentir e de expressar o que sentiu, com condições de reconhecer, nas aulas de literatura, um envolvimento de subjetividades que se expressam pela tríade obra/autor/leitor, por meio de uma interação que está presente na prática de leitura. A escola, portanto, deve trabalhar a literatura em sua dimensão estética (DCEs, 2008, p. 58).
\end{abstract}

As orientações dadas aos professores são para que a relação entre o leitor e a obra tenha espaço nas aulas de Língua Portuguesa a partir das concepções de Jauss e Iser. Tais teorias centramse no estudo de textos literários considerados clássicos, pois desconsideram que outras formas de narrativa contribuam para a formação do leitor. O documento propõe que a leitura de textos literários é uma forma de ativar a capacidade de pensamento crítico e a sensibilidade estética do leitor. A teoria do Letramento Literário não aparece neste documento, sendo assim outras formas de ficção aparecem somente na lista de conteúdos curriculares como possíveis gêneros a serem trabalhados, geralmente submetidos a análises linguísticas.

As DCEs de Língua Estrangeira Moderna têm uma base parecida com a da Língua Portuguesa, uma preocupação com o ensino de gêneros e a relação dialógica da linguagem. Em uma breve retomada histórica incluída no documento, vemos que o ensino de Língua Inglesa foi inserido no currículo das escolas brasileiras em 1809, e, então, o ensino dessa língua objetivava aproximar os estudantes de consagradas obras literárias escritas em inglês. Com o tempo, o foco das aulas passou a ser a questão linguística permeada por diferentes abordagens. A proposta metodológica das DCEs prevê um ensino de Língua Inglesa voltado para os gêneros discursivos de diferentes esferas sociais, a fim de possibilitar ao aluno interagir em diversos contextos e ter contato com outras culturas. A leitura parte das mesmas concepções das Diretrizes para o ensino de Língua Portuguesa, com a divergência de que os alunos não têm muito conhecimento de inglês e neste ponto o professor deve fazer um trabalho diferenciado, no qual a língua materna poderá ser utilizada em alguns momentos. O texto literário aparece, com uma pequena menção, como um gênero discursivo em meio a tantos outros, que também pode proporcionar a reflexão crítica:

\footnotetext{
Nos textos de literatura, as reflexões sobre a ideologia e a construção da realidade fazem parte da produção do conhecimento, sempre parcial, complexo e dinâmico, dependente do contexto e das relações de poder. Assim, ao apresentar textos literários aos alunos, devem-se propor atividades que colaborem para que ele analise os textos e os perceba como prática social de uma sociedade em um determinado contexto sociocultural (DCEs, 2009, p. 67).
}

O texto literário segue a proposta de trabalho dos outros textos, sem considerar suas características peculiares, estéticas, recepcionais, etc. Dessa forma, percebemos que não há espaço para as literaturas em língua inglesa. A leitura literária é preocupação apenas na disciplina de Língua 
Portuguesa, quando textos ficcionais diversos poderiam ser utilizados no ensino de Língua Inglesa, os mesmos que circulam cotidianamente entre os jovens, a partir dos estudos de letramentos, propiciando maior conhecimento cultural e social aos alunos.

\section{CONSIDERAÇÕES FINAIS}

Apesar de a acessibilidade a textos produzidos em língua inglesa estar crescendo no Brasil, seja na forma impressa ou em outros multimeios, como teatro, filmes, histórias em quadrinhos, publicações online, as LLI estão distantes das salas de aula do ensino público. De acordo com os PCNs e as DCEs, a preocupação nas aulas de Língua Inglesa têm sido principalmente linguísticas, com o texto literário integrado ao ensino como mais um gênero discursivo em meio a tantos outros. Até mesmo nos cursos de Letras de dupla licenciatura (português-inglês) as disciplinas de LLI não costumam ter muito espaço, isto porque um mesmo questionamento é feito pelos acadêmicos: Por que estudar LLI? Como irei aplicá-la em sala de aula no Ensino Fundamental e no Ensino Médio? Estas perguntas se repetem pelo fato de os acadêmicos terem contato com estas literaturas, porém, quando formados e atuando, tendem a não a utilizar nas aulas de Língua Inglesa na educação básica. Não a utilizam porque têm de seguir as diretrizes para o ensino impostas pelo governo, as quais, como mostramos, não sugerem o emprego das LLI nas aulas.

Acreditamos que a presença das LLI seria maior na educação básica se teorias voltadas para novos letramentos fossem inseridas nos documentos que regem o ensino e implantadas no ambiente escolar, abrindo espaço para outras formas de ficção além das obras "clássicas". A contribuição da leitura de textos em língua inglesa a partir dos letramentos é diversificada, pois questões como identidade, nacionalidade e cultura são ressaltadas e discutidas, levando o estudante a lidar com as diferenças cada vez mais presentes em nosso cotidiano devido ao contato cada vez maior com outras sociedades, propiciado principalmente pela Internet.

Para os professores de LLI, esta é uma forma de mostrar que as LLI estão em plena circulação no Brasil, ainda que em formas não-institucionalizadas, e também expandir seus estudos para outros meios, além do grafado, que apesar de alguns serem considerados alienadores por fazerem parte da indústria cultural, têm sido a preferência do público adolescente leitor brasileiro e podem ser criticamente abordados pela teoria do Letramento Literário. Não queremos, de forma alguma, banir o estudo de clássicos literários das escolas ou universidades. Estes, na verdade, já têm seu espaço garantido e defendido, são constantemente estudados e suas qualidades sempre ressaltadas. Os alunos devem conhecer os clássicos como parte de sua formação humana, porém as 
características necessárias para a "boa leitura" da literatura erudita dificilmente um adolescente possui, pela pouca experiência de vida. Sendo assim, além de expor os estudantes a clássicos, acreditamos ser relevante guiar suas outras leituras ficcionais por meio das aulas de língua inglesa.

As políticas públicas da educação afirmam que a língua inglesa faz parte do ensino escolar por ser utilizada pelos brasileiros no mundo globalizado, para o trabalho e a comunicação com pessoas de outros países. As LLI talvez estejam ainda mais inseridas no cotidiano dos brasileiros e não são consideradas relevantes, nos perguntamos se é pelo fato de os meios em que circulam fazerem parte da indústria cultural; se é por serem literatura, já que os textos literários são pouco valorizados em nosso país; ou se é devido ao discurso de colonização americana e inglesa. Seja qual for a razão maior, rejeitar os textos ficcionais produzidos em língua inglesa não é a solução, pois proibidos dentro da escola, estes circulam além muros institucionais.

\section{REFERÊNCIAS BIBLIOGRÁFICAS}

BRASIL. Secretaria de Educação Fundamental. Parâmetros curriculares nacionais: terceiro e quarto ciclos do ensino fundamental: língua portuguesa. Brasília: MEC/SEF, 1998.

BRASIL. Secretaria de Educação Fundamental. Parâmetros curriculares nacionais: terceiro e quarto ciclos do ensino fundamental: língua estrangeira. Brasília: MEC/SEF, 1998.

BRASIL. Secretaria de educação média e tecnológica. Parâmetros curriculares nacionais do ensino médio. Ministério da educação. Brasília: MEC, 2000.

CANCLINI, Néstor García. Leitores, espectadores e internautas. São Paulo: Iluminuras, 2008.

CANDIDO, Antonio. A literatura e a vida social. In: Literatura e sociedade: estudos de teoria e história literária. 7. ed. São Paulo: Ed. Nacional, 1985. p. 17-39.

CANDIDO, Antonio. A literatura e a formação do homem. In: Textos de intervenção. São Paulo: Duas Cidades Ed. 34, 2002.

COMPAGNON, Antoine. O demônio da teoria: literatura e senso comum. Trad. De Cleonice Paes Barreto Mourão; Consuelo Fontes Santiago. Belo Horizonte: Ed. UFMG, 2001.

CULLER, Jonathan. Teoria literária: uma introdução. São Paulo: Beca Produções Culturais Ltda., 1999.

EAGLETON, Terry. Teoria da literatura: uma introdução. São Paulo: Martins Fontes, 1983.

FESTINO, Cielo G. Uma abordagem crítica da disciplina "Literatura Inglesa": metáforas de dominação e subversão. In: Revista Crop, n. 13, p. 174- 192, 2008. 
HANSEN, João Adolfo. Reorientações no campo da leitura literária. In: ABREU, Márcia; SCHAPOCHNIK, Nelson (Orgs.). Cultura letrada no Brasil: objetos e práticas. Campinas, SP: Mercado de Letras, 2005. P. 13-44

JUNG, Neiva. Identidades sociais na escola: gênero, etnicidade, língua e as práticas de letramento em uma comunidade rural multilíngüe. Porto Alegre, UFRGS, 2003. Tese (Doutorado). Universidade Federal do Rio Grande do Sul. Porto Alegre, 2003.

KLEIMAN, Angela B. Modelos de letramento e as práticas de alfabetização na escola. In:

(Org.). Os significados do letramento: uma nova perspectiva sobre a prática social da escrita. Campinas, SP: Mercado de Letras, 1995. p. 15-61

MAFRA, Núbio Delanne Ferraz. Leituras à revelia da escola. Londrina: Eduel, 2003.

MENEZES DE SOUZA, L. Editor's preface. In: Critical Literacy: Theories and Practices, vol. 1, n. 1, p. 4-5, July 2007. Disponível em: 〈http://criticalliteracyjournal.org〉. Acesso em: 18 nov. 2011.

MONTE MÓR, W. Investigating critical literacy at the university in Brazil. In: Critical Literacy: Theories and Practices, vol. 1, n. 1, p. 41-51, July 2007. Disponível em: <http://criticalliteracyjournal.org>. Acesso em: 18 nov. 2011.

PARANÁ. Secretaria de Estado da Educação. Diretrizes Curriculares da Educação Básica: Língua Portuguesa. Curitiba: SEED, 2008.

PARANÁ. Secretaria de Estado da Educação. Diretrizes Curriculares da Educação Básica: Língua Estrangeira Moderna. Curitiba: SEED, 2009.

ROCCO, Maria Thereza Fraga. Literatura/Ensino: uma problemática. 2. ed. São Paulo: Editora Ática, 1992.

ROJO, Roxane. Letramento(s): práticas de letramento em diferentes contextos. In:

Letramentos múltiplos, escola e inclusão social. São Paulo: Parábola Editorial, 2009. P. 95-127

SIGNORINI, Inês. Letramento e (in)flexibilidade comunicativa. In: KLEIMAN, Ângela B. (Org.). Os significados do letramento: uma nova perspectiva sobre a prática social da escrita. Campinas, SP: Mercado de Letras, 1995. p. 161-199.

STREET, Brian V. Literacy in theory and practice. New York: Cambridge University Press, 1984. Cross-cultural approaches to literacy. New York: Cambridge University Press, 1993.

VERSIANI, Zélia. Escolha literárias e julgamento de valor por leitores jovens. In: PAIVA, Aparecida et. al. Literatura e letramento: espaços, suportes e interfaces. Belo Horizonte: Autêntica, 2003. p. 21-34.

WIELEWICKI, Vera Helena Gomes. Literatura e sala de aula: síncopes e contratempos. A agência discente e as literaturas de língua inglesa em cursos de licenciatura em letras. 2002. Tese (Doutorado) - Faculdade de Filosofia, Letras e Ciências Humanas de São Paulo, Universidade Estadual de São Paulo, São Paulo, 2002. 
WIELEWICKI, Vera Helena Gomes. Reading foreign language literature at university level in Brazil: developing critical readers. In: Critical Literacy: Theories and Practices, vol. 1, n. 1, p. 4151, July 2007. Disponível em: <http://criticalliteracyjournal.org>. Acesso em: 18 nov. 2011.

ZAPPONE, Mirian Hisae Yaegashi. Fanfics - um caso de letramento literário na cibercultura? Letras de Hoje, Porto Alegre, v. 43, n. 2, p. 29-33, abr./jun. 2008. 